\title{
Author Correction: Parkinson disease-associated cognitive impairment
}

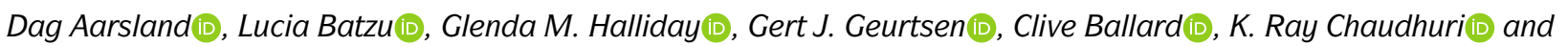
Daniel Weintraub

Nature Reviews Disease Primers https://doi.org/10.1038/s41572-021-00280-3, published online 01 July 2021.

In the original version of this Primer the hyperlink for the MoCA test was incorrectly written as www.mocatest.com, whereas it should have been www.mocatest.org. This has been corrected in the HTML and PDF versions of the manuscript.

https://doi.org/10.1038/s41572-021-00292-z I Published online: 13 July 2021

(c) Springer Nature Limited 2021 